\title{
EDUCAÇÃO EM SAÚDE NO ENSINO DE GRADUAÇÃO EM ENFERMAGEM
}

HEALTH EDUCATION IN UNDERGRADUATE NURSING TEACHING

\section{EDUCACIÓN EN SALUD EN LA ENSEÑANZA EN LA GRADUACIÓN EN ENFERMEIRA}

\author{
Marcela Nojiri Moreira ${ }^{1}$, Maria Paula Custódio Silva ${ }^{2}$, Ana Paula Geralda Moreira Duarte ${ }^{3}$, \\ Marina Pereira Resende ${ }^{4}$, Jesislei Bonolo do Amaral ${ }^{5}$, Divanice Contim ${ }^{6}$
}

\begin{abstract}
RESUMO
Objetivo: identificar as disciplinas que nos seus conteúdos apresentam temas sobre educação em saúde. Método: Estudo qualitativo, na modalidade documental, constituído de fontes primárias produzidas entre 2010 e 2015. Os dados foram submetidos à técnica de Análise Textual Discursiva. Resultados: duas disciplinas apresentam na ementa o descritor exato educação em saúde, esses componentes situavam-se no quinto e no décimo período, nove referências básicas traziam nos seus títulos o descritor educação em saúde e um objetivo do plano pedagógico expressava o descritor educação em saúde. Conclusão: constatou-se que a educação em saúde é importante ferramenta de construção profissional, ocupando posição de destaque na formação de acadêmicos de enfermagem, no entanto, sendo necessário rediscutir seu conceito.
\end{abstract}

Descritores: Educação em saúde; Educação em Enfermagem; Educação Superior; Currículo.

\begin{abstract}
Objective: To identify the disciplines that in their contents present themes on health education. Methods: Qualitative study, in the documentary mode, consisting of primary sources produced between 2010 and 2015. The data were submitted to the Discursive Textual Analysis technique. Results: Two disciplines present in the menu the exact descriptor health education, these components were in the fifth and tenth period, nine basic references had in their titles the descriptor education in health and one objective of the pedagogical plan expressed the descriptor education in health. Conclusion: It was verified that health education is an important tool of professional construction, occupying a prominent position in the training of nursing students; however, it is necessary to rediscuss its concept.
\end{abstract}

Descriptors: Health education; Education; Nursing; Education; Higher; Curriculum.

\footnotetext{
${ }^{1}$ Enfermeira. UFTM.

${ }^{2}$ Enfermeira. Especialista em Neonatologia e Mestranda em Atenção à Saúde. UFTM.

${ }^{3}$ Mestranda em Educação Ambiental e Sustentabilidade. Escola Superior de Educação de Viseu. Portugal.

${ }^{4}$ Doutora. Enfermeira. Coordenadora do Curso de Graduação em Enfermagem. UFTM.

${ }^{5}$ Doutora. Enfermagem. Departamento de Enfermagem Hospitalar. UFTM.

${ }^{6}$ Doutora. Enfermagem. Departamento de Enfermagem Hospitalar. UFTM.
} 


\section{RESUMEN}

Objetivo: Identificar las disciplinas que en sus contenidos presentan temas sobre educación en salud. Métodos: Estudio cualitativo, en la modalidad documental, constituido de fuentes primarias producidas entre 2010 y 2015. Los datos fueron sometidos a la técnica de Análisis textual Discursivo. Resultados: Y en el décimo período, nueve referencias básicas traían en sus títulos el descriptor educación en salud y un objetivo del plan pedagógico expresaba el descriptor educación en salud. Conclusión: Se constató que la educación en salud es importante herramienta de construcción profesional, ocupando posición destacada en la formación de académicos de enfermería, sin embargo, siendo necesario rediscutir su concepto.

Descriptores: Educación en salud; Educación en Enfermería; Educación superior; Curriculum.

\section{INTRODUÇÃO}

As questões que envolvem o ensino e a aprendizagem ocorrem nas mais variadas situações da realidade brasileira e do mundo. Os processos de ensino e aprendizagem oferecidos nas escolas, universidades, cursos técnicos e/ou profissionalizantes, na área da saúde, podem ser vistos como um campo de práticas que ocorre por meio das relações sociais estabelecidas pelos profissionais e usuários. ${ }^{1}$

Nesse contexto, a Educação em Saúde é entendida como um processo educativo de construção de conhecimentos em saúde que visa à apropriação temática pela população, tornando-se um conjunto de práticas do setor que contribui para aumentar a autonomia das pessoas no seu cuidado. Por isso, busca alcançar uma atenção de acordo com suas necessidades, como também potencializar o exercício do controle social sobre as políticas e os serviços de saúde para que estes respondam às necessidades da população. ${ }^{2}$
A mesma é um recurso no qual, o conhecimento produzido pela ciência na área da saúde, intermediado pelos profissionais, objetiva atingir a vida cotidiana das pessoas para melhor compreensão dos condicionantes da relação saúde-doença, oferece subsídios para que novos hábitos e condutas de saúde possam ser adotados. ${ }^{3}$

Pesquisadores têm revelado preocupações acerca do objeto da educação em saúde no ensino de enfermagem em estudos que expressaram, em síntese, as relações entre a prática educativa desenvolvida pelos profissionais de saúde e a realidade do preparo do enfermeiro na graduação para desempenhar o papel de educador. Ao analisar essas publicações, observou-se o papel relevante que está possui na prática social dessa categoria profissional. Ainda que tais práticas permaneçam restritas à abordagem biomédica, focadas nos aspectos preventivos, exigindo a compreensão de que as peculiaridades do processo educativo 
exigem uma capacitação específica que não

é inerente à formação técnica do enfermeiro. ${ }^{4,5,6}$

A partir da implementação das Diretrizes Curriculares Nacionais (DCN) para os Cursos de Graduação em Enfermagem, publicada pelo Conselho Nacional de Educação (CNE) em 2001. ${ }^{7}$ Indica-se que ao final da formação profissional, os enfermeiros apresentem competências e habilidades para atuar de acordo com a complexidade e desafios apresentados no Sistema Único de Saúde (SUS).

Diante de tais considerações, este estudo busca desvelar a educação em saúde enquanto componente curricular abrangente na formação do enfermeiro. Este processo é conduzido por meio da ação educativa, resultante da prática reiterativa ou criadora comprometidas com as diretrizes do projeto político do SUS, nas quais constituem condições favoráveis ao desenvolvimento de práticas educativas não tradicionais. Nessa direção, a educação em saúde necessita de estudos que vislumbrem atuais demandas básicas relacionadas à metodologia aplicada pelos profissionais de saúde para o alcance dos objetivos mais duradouros, minimizando os entraves na sua implantação, bem como as adequações necessárias para sua viabilização. ${ }^{3,4}$
Este estudo tem como questão norteadora: Como os conteúdos de educação em saúde estão inseridos nas disciplinas do curso de enfermagem da UFTM? Para responder ao questionamento, delineou-se o seguinte objetivo: identificar as disciplinas que nos seus conteúdos apresentam temas sobre educação em saúde.

\section{MÉTODO}

Trata-se de um estudo documental que objetiva descrever e compreender um fato histórico a partir de diversos documentos, utilizando-se métodos e técnicas que vão desde a coleta de informações, passando por etapas e procedimentos que permitem categorizar e, por fim, analisar os dados encontrados. Os estudos de natureza documental são inovadores, pois, os mesmos documentos podem ser investigados por pessoas diferentes em outros momentos a fim de serem reexaminados, reinterpretados de forma complementar, ou ainda, diferente da primeira análise realizada. ${ }^{8}$

As fontes primárias utilizadas foram encontradas nos arquivos do Curso de Graduação em Enfermagem da Universidade Federal do Triângulo Mineiro - UFTM, mediante autorização de seus gestores. Essas foram constituídas por 
planos de ensino que em seus conteúdos traziam referências aos conceitos teóricos e práticos de educação em saúde.

A coleta dos dados foi realizada nos meses de janeiro a março de 2018, por meio da captura dos planos de ensino das disciplinas, no qual se extraiu os seguintes achados: semestre de aplicação, carga horaria teórica e prática, objetivos, ementas e referências que indicassem o tema de Educação em Saúde. Após a identificação dos documentos, realizou-se a leitura com a finalidade de efetuar o fichamento dos documentos. Esses foram selecionados, organizados e catalogados. Para a catalogação apontou-se cada fonte com as principais informações contidas. Esses apontamentos foram reunidos com a finalidade de se estabelecer relações de similaridade e pertinência temática aos dados colhidos.

A delimitação temporal do estudo percorreu o período de 2010, ano de implantação da nova grade curricular, em consonância com o Parecer CNE/CES n ${ }^{\circ}$ 213/2008, dispondo sobre a carga horária e procedimentos relativos à integralização e duração dos cursos de graduação, bacharelados para curso da área da saúde, até a data limite de 2015, ano de conclusão da primeira turma da nova matriz curricular. 9
Os dados foram analisados segundo a técnica de Análise Textual Discursiva ${ }^{10}$ como um processo auto-organizado de produção de novas compreensões em relação aos fenômenos que examina. Essa técnica é concebida a partir de dois movimentos opostos: o primeiro de desconstrução, de análise propriamente dita e o segundo reconstrutivo, um movimento de síntese. Essa técnica consiste na fragmentação do texto transformando as informações em unidades elementares denominadas de unidades de significado ou unidades de sentido. Para identificar as unidades utilizou-se letras: PE (plano de ensino), acompanhada de D (disciplina) e de numeração (PED1 PED2, PED3...), conforme a ordem de catalogação dos documentos.

$\mathrm{O}$ estudo seguiu as exigências da Resolução 466/2012 do Conselho Nacional de Saúde e encontra-se registrado no Comitê de Ética em Pesquisa da Universidade Federal do Triângulo Mineiro sob CAAE: 67860917.6.0000.5154

\section{RESULTADOS}

O curso de Enfermagem teve a sua primeira turma de ingressantes em fevereiro de 1989, tendo passado por modificações curriculares, coincidindo com uma fase de maturidade, evidenciada pela estruturação e 
organização do curso, demonstrada na superação das adversidades, nas conquistas e nos avanços alcançados em 2005, ano da transformação da Faculdade de Medicina do Triângulo Mineiro (FMTM), em Universidade Federal do Triângulo Mineiro (UFTM). Registra-se o impacto causado pela inserção dos enfermeiros formados por esse curso atuando nos níveis de atenção primária, secundária e terciária, com consequente melhoria na qualidade dos serviços prestados à população.

Atualmente, curso tem duração de dez semestres, tendo no currículo obrigatório 47 disciplinas, sendo que, 16 pertencem ao módulo básico e 31 são de responsabilidade de dois departamentos que representam áreas de conhecimento na Enfermagem. Das disciplinas analisadas, duas apresentam na ementa o descritor exato educação em saúde. $\mathrm{Na}$ grade curricular esses componentes situavam-se no quinto e no décimo período.

Quanto à carga horária dessas disciplinas: Educação em Saúde na Enfermagem com 75 horas/aula, assim distribuídas em 40 horas/aula teóricas e 35 horas/aula práticas e Estágio Curricular Supervisionado na Área Hospitalar com 480 horas /aula práticas. Nove referências básicas traziam nos seus títulos o descritor educação em saúde.
Essas referências estavam nas disciplinas específicas da área da enfermagem. Quanto às referências complementares, foram encontrados cinco títulos com o duplo termo educação em saúde. Um único objetivo do curso expressava o descritor educação em saúde. Foram observados a utilização de descritores como: educação continuada, educação permanente, formação contínua, educação sanitária, educação para a saúde comunitária, educação para a saúde, educar para a saúde. Ressalta-se que esses descritores estavam distribuídos em 12 disciplinas de diferentes contextos como, ementas, objetivos e conteúdos. A partir desse arcabouço teórico-metodológico, emergiu a categoria temática: o ensino de enfermagem e as interfaces com a educação em saúde.

Os documentos analisados Apontam:

- Aspectos históricos e conceituais de Educação em saúde. (PED2)

- Nos documentos analisados registram a relação sobre a preparação de graduandos a realizar uma efetiva formação para a educação em saúde, alcançando a almejada resolutividade:

- Preparar o aluno para atuar como membro qualificado e competente na equipe multiprofissional de 
saúde e educação em saúde.

(PED1)

- O educador e o quadro conceitual em que se desenvolve a Educação em Saúde. (PED3)

- A prática educativa na promoção da saúde, planejamento, execução e avaliação de programas educativos em saúde. (PED2)

- Desenvolvimento de habilidades para as atividades de Educação Permanente e Educação em Saúde. (PED4)

\section{DISCUSSÃO}

A educação em saúde conheceu, no último século, profundas mudanças, tanto no plano conceitual como no das práticas, fruto das transformações por quais passaram a humanidade em termos políticos, econômicos e sociais. Constituise num campo de conhecimento e de prática do setor saúde que tem a finalidade de promover a saúde e atuar na prevenção de doenças, integrando saberes, científico e popular, na tentativa de colaborar com o indivíduo para uma maior participação, responsável e autônoma, frente à saúde no cotidiano. $^{11,12}$

No contexto histórico, a educação em saúde teve sua retomada no movimento da Reforma Sanitária, que, em meados da década de 1980, quando da realização da VIII Conferência Nacional de Saúde (1986). Esse movimento foi demarcado pelo momento político do setor saúde que conjugava o rompimento do pensamento biomédico para uma fase participativa e de escuta social. Outro fato sócio histórico foi a promulgação da Constituição de 1988 que resgatou a saúde como um direito e processo de cidadania, especificado, no Artigo 196, onde saúde é "direito de todos e dever do Estado". 13

Com a promulgação da Lei Federal $\mathrm{n}^{\circ} 8.080 / 90$, observa-se a necessidade de adequação da formação dos recursos humanos para atendimento das necessidades sociais em saúde dos problemas gerenciais do sistema de saúde. Ressalta-se que essa ação política ampliase a integração ensino-serviço, e as instituições de formação acadêmica para a área da saúde, sobretudo as universidades públicas. $^{11}$

Quanto à formação brasileira na área da saúde, ao longo dos tempos, avança-se no sentido de atender as orientações políticas do setor da saúde, sobretudo no repensar nas necessidades impostas pela implementação do SUS. ${ }^{13}$

Há um consenso entre os observadores da reforma sanitária brasileira de que a formação de recursos humanos para o setor é um dos graves problemas do 
SUS. O despreparo dos profissionais recémformados para atuarem na complexidade inerente do sistema de saúde, compreenderem sua gestão e a ação do controle da sociedade sobre o setor é uma constatação frequente, sendo esse um dos nós que precisam ser desatados na formação. ${ }^{11,13}$

Nos cursos de graduação na área da saúde, supõe-se que a orientação, obedeça às regras, normas e protocolos, garanta a formação de profissionais para atuarem frente às necessidades do setor, estabelecendo "parâmetros" e determinando "caminhos" para se proporem projetos de ensino de graduação com vistas às mudanças das práticas de cuidado em saúde e enfermagem. ${ }^{14,15}$

As diretrizes curriculares nacionais dos cursos da área da saúde, em vários itens do artigo $5^{\circ}$, reiteram a importância da formação superior: propiciar competências e habilidades para o trabalho em equipe multiprofissional e atuar de forma a garantir a integralidade da assistência. Para a formação do enfermeiro, são enfatizados aspectos como reconhecer a saúde e condições dignas de vida como direito e atuar de forma a garantir a integralidade da assistência, entendida como conjunto articulado e contínuo das ações e serviços preventivos e curativos, individuais e coletivos, exigidos para cada caso em todos os níveis de complexidade do sistema; assumindo o compromisso ético, humanístico e social com o trabalho multiprofissional em saúde e integrar as ações de enfermagem às ações multiprofissionais. ${ }^{9,14,15}$

Dessa forma, o movimento de mudanças curriculares na saúde, e na enfermagem em particular, elaborou estruturas formativas que contemplassem a interdisciplinaridade curricular, como estratégia passível de atender ao ensino do objeto complexo que é o processo saúdedoença, e assim, responder às questões mais amplas do setor, em particular ao princípio da integralidade do sistema, além de atender às proposições das $\mathrm{DCN}$.

Registra-se que um estudo sobre o ensino de educação em saúde em cursos de graduação de enfermagem no estado de São Paulo, de instituições públicas e privadas, evidenciou-se que este ainda permanece vinculado ao modelo biomédico preventivo, e que as concepções de educação crítica e as práticas educativas populares são escassas, por um lado, devido à deficitária formação política dos docentes, por outro, em consequência do enfrentamento de um contexto acadêmico de implementação do ideário neoliberal. ${ }^{5}$

Estudo realizado numa Instituição privada de Ensino Superior no nordeste do Brasil com acadêmicos do curso de 
enfermagem apontou a existência de convergências entre o modelo biomédico e a execução das atividades educativas, no entanto, é evidenciada como importante ferramenta de construção profissional. Conclui-se que a Educação em Saúde ocupa posição de destaque na formação de acadêmicos de enfermagem, no entanto, sendo necessário rediscutir seu conceito. ${ }^{15}$

Dentre as propostas evidenciadas no ensino de Educação em Saúde encontra-se a prática educativa na promoção da saúde, embora essa possua métodos e segmentos distintos, não se limita apenas a transmitir conhecimento à comunidade. Observa-se um hiato entre a teoria e prática, uma vez que a esta atividade não agregam-se os pilares fundamentais de autonomia e empoderamento, enfraquecendo deste modo a credibilidade dos usuários na ferramenta de promoção à saúde. ${ }^{14,16}$

Desse modo, a incorporação no ensino de Educação em Saúde de ações voltadas à promoção da saúde das populações sem a égide do modelo tecnicista deve ir além da transmissão de conhecimento, estabelecendo vínculo afetivo com os sujeitos envolvidos, reduzindo assim o distanciamento entre as instituições de saúde e a população. ${ }^{15}$

A educação em saúde proporciona o desenvolvimento de habilidades para as atividades de educação permanente, constituindo parte do pensar e do fazer dos profissionais, com a finalidade de propiciar o crescimento pessoal e profissional destes, bem como contribuir para a organização do processo de trabalho, uma vez que se desenvolvem a partir de problemas diários identificados na realidade. ${ }^{17,18}$

No entanto, as concepções sobre os valores em práticas educativas em saúde voltadas ao desenvolvimento profissional são distintas entre os cursos da área da saúde e os da área das ciências sociais e humanas. Nos cursos de enfermagem ocorre maior evolução dos valores, nos quais se enfatizam os valores social, holístico, autonomia e democracia. ${ }^{18}$

\section{CONCLUSÕES}

No processo de formação em enfermagem tem-se observado mudanças que seguem as exigências das políticas de educação e de saúde, bem como as demandas do mercado de trabalho de cada época. Nesse contexto o ensino de educação em saúde requer um processo teóricoprático de avaliação a partir da construção de estratégia de enfrentamento da realidade e de sustentação do SUS. Nota-se que, atualmente, são grandes os esforços das Instituições de Ensino Superior em atender as diretrizes do Ministério da Educação no tocante à formação de profissionais mais 
comprometidos com a humanização do atendimento e da relação com o cliente.

Neste sentido, a inserção de atividades de Educação em Saúde na formação de estudantes da área de saúde é uma importante ferramenta de construção do futuro profissional, pois vista como uma prática social pode ser pensada como um modo de promover a reflexão e a consciência crítica das pessoas sobre sua situação de vida.

O recorte feito por este estudo, com base na análise dos planos de ensino da grade curricular, não esgota as possibilidades de investigação desta temática. Fica evidente a necessidade de novas análises, a serem realizadas por outros sujeitos que poderiam ser distintas das apresentadas aqui. Entretanto, este estudo poderá contribuir para o aprimoramento do currículo dos cursos de graduação em enfermagem, uma vez que apresentam as dificuldades e fragilidades percebidas no modelo pensado para essa pesquisa.

\section{REFERÊNCIAS:}

1. Pinafo E, Nunes EFPA, González AD, Garanhani ML. Relações entre concepções e práticas de educação em saúde na visão de uma equipe de saúde da família. Trab Educ Saúde [Internet]. 2011 [citado em 23 abr 2018]; 9(2):201-21. Disponível em: http://www.scielo.br/pdf/tes/v9n2/03.pdf
2. Ministério da Saúde (Brasil), Secretaria de Vigilância em Saúde, Secretaria de Atenção à Saúde. Política nacional de promoção da saúde [Internet]. 3ed. Brasília, DF: Ministério da Saúde; 2010 [citado em 04 abr 2018]. (Série B. Textos básicos de saúde. Série Pactos pela saúde, v.7). Disponível em:

http://bvsms.saude.gov.br/bvs/publicacoes/ politica_nacional_promocao_saude_3ed.pd $\mathrm{f}$

3. Salci MA, Maceno P, Rozza SG, Silva DMGV, Boehs AE, Heidmann ITSB. Educação em saúde e suas perspectivas teóricas: algumas reflexões. Texto \& Contexto Enferm. [Internet]. 2013 [citado em 04 abr 2018]; 22(1):224-30. Disponível em:

http://www.scielo.br/pdf/tce/v22n1/pt 27.p $\underline{\mathrm{df}}$

4. Ferreira VF, Lopes MMB.

Educação em saúde: desafios para uma prática inovadora. Rev Enferm UFPE on line [Internet]. 2013 [citado em 18 jun 2015]; 7(esp):5834-6. Disponível em: https://periodicos.ufpe.br/revistas/revistaen fermagem/article/viewFile/11867/14313 5. Figueira $\mathrm{AB}$, Amestoy $\mathrm{SC}$, Cecagno D, Tristão FS, Trindade LL, Correa VA. Visão do enfermeiro frente à prática da educação em saúde no ambiente hospitalar. Cogitare Enferm. [Internet]. 2013 [citado em 21 maio 2016]; 18(2):3010-6. Disponível em: https://revistas.ufpr.br/cogitare/article/view 132580

6. Pennafort VPS, Silva ANS, Queiroz MVO. Percepções de enfermeiras acerca da prática educativa no cuidado hospitalar a crianças com diabetes. Rev Gaúch Enferm. [Internet]. 2014 [citado em 07 ago 2016]; 35(3):130-6. Disponível em: http://www.scielo.br/pdf/rgenf/v35n3/pt_1 983-1447-rgenf-35-03-00130.pdf

7. Conselho Nacional de Educação. Câmara de Educação Superior. Resolução $\mathrm{n}^{\mathrm{o}} 4$, de 6 de abril de 2009. Dispõe sobre carga horária mínima e procedimentos relativos à integralização e duração dos cursos de graduação em Biomedicina, 
Ciências Biológicas, Educação Física, Enfermagem, Farmácia, Fisioterapia, Fonoaudiologia, Nutrição e Terapia Ocupacional, bacharelados, na modalidade presencial [Internet]. DOU, Brasília, DF, 7 abr 2009 [citado em 12 mar 2018].

Disponível em:

http://portal.mec.gov.br/dmdocuments/rces 004_09.pdf

8. Godoy JMT. Alguns desafios dos estudos de historiografia. Proj Hist.

[Internet]. 2010 [citado em 11 maio 2018]; 41:195-214. Disponível em:

https://revistas.pucsp.br/index.php/revph/ar ticle/download/6539/4738

9. Conselho Nacional de Educação. Câmara de Educação Superior. Resolução $\mathrm{n}^{\mathrm{o}} 3$ de 7 de novembro de 2001. Institui Diretrizes Curriculares Nacionais do Curso de Graduação em Enfermagem [Internet]. Brasília, DF: CNE; 2001 [citado em 06 ago 2013]. Disponível em:

http://portal.mec.gov.br/dmdocuments/rces 004_09.pdf

10. Moraes R, Galiazzi M. Análise textual discursiva. 2ed. Ijuí, RS: Unijuí; 2011.

11. Moutinho CB, Almeida ER, Leite MTS, Vieira MA. Dificuldades, desafios e superações sobre educação em saúde na visão de enfermeiros de saúde da família. Trab Educ Saúde [Internet]. 2014 [citado em 21 abr 2018]; 12(2):253-72. doi:

http://dx.doi.org/10.1590/ S198177462014000200003

12. Silva LD, Beck CLC, Dissen CM, Tavares JP, Budó MLD, Silva HS. O enfermeiro e a educação em saúde: um estudo bibliográfico. Rev Enferm UFSM. [Internet]. 2012 [citado em 10 abr 2018]; 2(2):412-9. Disponível em:

https://periodicos.ufsm.br/reufsm/article/vi ew/2676/3769

13. Paiva CHA, Teixeira LA. Reforma sanitária e a criação do Sistema Único de Saúde: notas sobre contextos e autores. Hist Ciênc Saúde-Manguinhos [Internet]. 2014 [citado em 11 maio 2018]; 21(1):1535. Disponível em: http://www.scielo.br/pdf/hcsm/v21n1/0104 -5970-hcsm-21-1-00015.pdf

14. Colomé JS, Oliveira DLLC.

Educação em saúde: por quem e para quem? a visão de estudantes de graduação em enfermagem. Texto \& Contexto Enferm. [Internet]. 2012 [citado em 04 abr 2018]; 21(1):177-84. Disponível em: http://www.scielo.br/pdf/tce/v21n1/a20v21 n1.pdf

15. Francisco GFP, Joselany AC, Juliana FM, Márcia BCA. Práticas educativas em saúde na formação de acadêmicos de enfermagem. Cogitare Enferm. [Internet]. 2015 [citado em 11 maio 2018]; 20(2):332-7. Disponível em: https://revistas.ufpr.br/cogitare/article/view File/39767/25546

16. Silva-Arioli IG, Schneider DR, Barbosa TM, Da Ros MA. Promoção e educação em saúde: uma análise epistemológica. Psicol Ciênc

Prof. [Internet]. 2013 [citado em 11 maio 2018]; 33(3):672-87. Disponível em: http://www.scielo.br/pdf/pcp/v33n3/v33n3 a12.pdf

17. Salum NC, Prado M. A educação permanente no desenvolvimento de competências dos profissionais de enfermagem. Texto \& Contexto Enferm. [Internet]. abr/jun 2014 [citado em 21 abr 2018]; 23(2):301-8. Disponível em: http://www.scielo.br/pdf/tce/v23n2/pt_010 4-0707-tce-23-02-00301.pdf

18. Sardinha PL, Cuzatis GL, Dutra CT, Tavares CMM, Dantas CAC, Antunes CE. Educación permanente, continuada y de servicio: desvelando sus conceptos. Enferm Glob. [Internet]. 2013 Ene [citado em 13 maio 2018]; 12(29):307-22.

Disponível em: http://scielo.isciii.es/scielo.php?script=sci_ arttext\&pid=S1695-

$61412013000100017 \& \operatorname{lng}=\mathrm{es}$.

RECEBIDO: $28 / 10 / 18$

APROVADO: $15 / 04 / 19$

PUBLICADO: 07/19 